\title{
Suffering in Silence: Reasons for Not Disclosing Depression in Primary Care
}

\author{
Robert A. Bell, PbD \\ Peter Franks, MD \\ Paul R. Duberstein, PbD \\ Ronald M. Epstein, MD \\ Mitcbell D. Feldman, MD, MPbil \\ Erik Fernandez y Garcia, MD, MPH \\ Richard L. Kravitz, MD, MSPH
}

\begin{abstract}
PURPOSE Depression symptoms are underreported by patients. We thus assessed individuals' reasons for not disclosing depression to their primary care physician.

METHODS We conducted a follow-up telephone survey of 1,054 adults who had participated in the California Behavioral Risk Factor Survey System. Respondents were asked about reasons for nondisclosure of depressive symptoms to their primary care physician, depression-related beliefs, and demographic characteristics. Descriptive and inferential statistical procedures were used to characterize perceived obstacles to disclosure.
\end{abstract}

RESULTS Of the respondents, $43 \%$ reported 1 or more reasons for nondisclosure. The most frequent reason was the concern that the physician would recommend antidepressants (22.9\%; 95\% confidence interval, 18.8\%-27.5\%). Reported reasons for nondisclosure of depression varied based on whether the respondent had a history of depression. For example, respondents with no depression history were more likely to believe that depression falls outside the purview of primary care $(P=.040)$ and more likely to fret about being referred to a psychiatrist $(P=.036)$. Respondents with clinically significant depressive symptoms rated 10 of 11 barriers to disclosure as more personally applicable than did those without symptoms (all $P$ values $\leq$.014). Number of reported disclosure barriers was predicted by demographic characteristics (being female, Hispanic, of low socioeconomic status), depression beliefs (depression is stigmatizing and should be under one's control), symptom severity, and absence of a family history of depression.

CONCLUSIONS Many adults subscribe to beliefs likely to inhibit explicit requests for help from their primary care physician during a depressive episode. Interventions should be developed to encourage patients to disclose their depression symptoms and physicians to ask about depression.

Ann Fam Med 2011;9:439-446. doi:10.1370/afm.1277.

\section{INTRODUCTION}

L

ifetime and 12-month prevalence of major depressive disorder (MDD) in the United States has been estimated to be $16.2 \%$ and see inside back cover or http.//www. annfammed.org/AJC/.

Conflicts of interest: Dr Epstein has given 2 talks on patient-pbysician communication sponsored by Merck, in which they had no role in content, and no products were discussed. Dr Kravitz has received research grant funding from Pfizer (ending in 2008) unrelated to depression care. The remaining authors bave no potential conflicts of interest to disclose.

\section{CORRESPONDING AUTHOR}

Robert A. Bell, PhD

Department of Communication

One Shields Ave

University of California, Davis

Davis, CA 95616

rabell@ucdavis.edu
$16.6 \%$, respectively. ${ }^{1}$ In one-fourth of primary care patients with MDD, the condition is not diagnosed, ${ }^{1}$ and a majority who seek help from a primary care physician do not receive appropriate treatment. ${ }^{2,3}$ Because patients are often treated in primary care, ${ }^{3}$ efforts have been made to improve recognition, treatment, and follow-up for patients with depression in general practice. ${ }^{4}$ Suboptimal levels of recognition and treatment are due to a variety of physician, health system, and patient factors. ${ }^{4-7}$

The present study is part of the formative research of a larger project that will develop and evaluate office-based interventions to encourage seeking care for depression. This research is grounded in a model that assumes self-disclosure of depression is a key step on the road to appropriate diagnosis and therapy. Physicians are more likely to initiate treatment when the patient provides recognizable clues to depression, ${ }^{8}$ discloses symptoms of depression, or directly requests help..$^{9,10}$ Encouraging disclo- 
sure requires that patients' barriers to the initiation of conversations about depression be understood. Our initial studies have identified potential barriers to disclosure and potential intervention strategies. ${ }^{11-14}$ The present research builds upon prior studies by examining the prevalence of perceived barriers in a general population survey.

Reasons why adults might not talk with their primary care physicians about their depression symptoms are numerous ${ }^{15}$ and include the belief that a primary care physician is an inappropriate source of care for emotional problems ${ }^{12,14}$; uncertainty about how to raise the topic of depression ${ }^{12}$; concerns about distracting the doctor from other, more medically salient health issues ${ }^{16}$; aversion to antidepressant medications ${ }^{17}$ and psychotherapy ${ }^{18}$; stigma stemming from either a diagnosis of depression or psychiatric treatment ${ }^{12,14,16}$; loss of emotional control ${ }^{19}$; and reluctance to discuss personal issues. ${ }^{19}$

Perceived barriers to disclosure might differ by personal experience with depression treatment and symptom severity. Individuals who have undergone treatment should have concerns about available depression treatments different from those of individuals who have not. Furthermore, those who have received medical treatment for depression would presumably have more positive outcome expectations than those who have not. We also anticipated that severity of current depressive symptoms would be associated with more perceived barriers to talking with one's doctor about depression symptoms. Such an expectation is suggested by social cognitive theory (SCT), which posits that a depressed mood lowers self-efficacy for performing challenging behaviors. ${ }^{20}$ Initiating a conversation about depression could be challenging for many patients. ${ }^{19,21}$ Finally, one might anticipate several other correlates of perceived barriers to disclosure, including standard demographic variables, health history and perceptions, beliefs about the nature and causes of depression, and insurance status. Prior studies have examined these and other predictors in relation to treatment preferences ${ }^{22}$ but not in relation to disclosure barriers.

We addressed 4 research questions: (1) What is the prevalence of perceived barriers to disclosure of depression to primary care physicians in the general population? (2) Do perceptions of barriers to disclosure differ between individuals with and without a history of depression? (3) Does severity of depression symptoms affect perceptions of these barriers? (4) What are the demographic and attitudinal predictors of perceived barriers to disclosure? The unique contribution of this study is that its results are based on a large, population-based survey sample that included adults with and without a history of depression.

\section{METHODS \\ Sampling Procedure}

The Institutional Review Board at the University of California, Davis, approved all procedures. A total of 1,054 respondents were interviewed by telephone from July through December 2008 in a follow-up survey. Specifically, respondents were randomly sampled from the group of individuals who had earlier participated in the 2008 California Behavioral Risk Factor Survey System (BRFSS), a cross-sectional random digit dial telephone survey. BRFSS respondents had been selected at random, were initially interviewed from January through June 2008, and had given permission to be contacted again. Because an equal probability sampling of BRFSS participants would have resulted in too few respondents with a history of depression treatment, respondents who reported a history of depression in the BRFSS survey were oversampled by a factor of 3 . This strategy allowed us to detect with $90 \%$ power a small difference ( 0.2 standard deviations) between those with $(\mathrm{n}=475)$ and without $(\mathrm{n}=579)$ a history of depression on any of our measures. When making population estimates, this overrepresentation of individuals with a history of depression was corrected via weighting.

\section{Survey Administration}

This survey was administered by a survey research organization based in Sacramento, California. Up to 15 attempts were made to contact each sampled respondent. Interviews took approximately 20 minutes. English- and Spanish-speaking interviewers were available; 52 interviews (4.9\%) were completed in Spanish. A response rate of $49 \%$ was obtained after excluding households of unknown eligibility.

\section{Measures}

We examined 5 sets of measures included in either the original BRFSS survey or the depression follow-up survey: demographic variables, perceived barriers to care seeking for depressive symptoms, health status measures, beliefs about depression, and anticipated reaction to a future diagnosis of depression. To measure perceived barriers to care seeking, respondents were presented with 11 reasons (described below) why one might not talk to their primary care physician about depression and asked to rate the personal applicability of each (applies a lot to you, applies a little to you, or does not apply at all to you). In most analyses, the individual items were analyzed. For one analysis we constructed a Perceived Barriers Index by counting across the 11 reasons (theoretical range: $0-11$ ) the number of applies-a-lot responses (Cronbach's $\alpha=.83$ ); an exploratory factor analysis showed these items to be unifactorial. 
With regard to health status, respondents completed single-item measures in which they were asked whether they were being treated for depression, had ever been treated for depression by a health care professional, or had a family member who was ever treated for depression (coded 1 for affirmative responses and 0 otherwise). They also rated their general health perception on a 5 -point scale ( $1=$ excellent to $5=$ poor $)^{23}$ and reported whether they had a regular source of care and health insurance (1 if yes, 0 otherwise). Current depression symptoms were assessed with the 9-item Patient Health Questionnaire (PHQ-9), which has been found to be a valid measure of depression symptomatology in primary care and population survey settings ${ }^{24,25}$; higher scores indicate great depression symptoms.

Several depression-related beliefs were assessed. Stigma was measured with 3,5-point Likert items taken from the work of Fogel and Ford $(\alpha=.54) .{ }^{26}$ The questionnaire also included items adapted from measures used in previous studies of illness representations in depression. ${ }^{27,28} \mathrm{On}$ the basis of a factor analysis (results not reported in tabular form), scales were constructed to assess the beliefs that depression has biomedical causes, is rooted in psychosocial issues, and is under a person's control. The biomedical causes measure consisted of 4 items (eg, "Chemical imbalances in the brain cause depression.") ( $\alpha=.70)$. The psychosocial causes measure was composed of 2 items (eg, "Depression is the result of problems in living, such as job stress, money problems, or conflicts with family.") $(\alpha=.68)$. The personal control measure consisted of 2 items (eg, "People with depression should be able to pull themselves out of it without professional help.") $(\alpha=.58)$. A single item was included to assess respondents' perceptions of the usual time course of depression (ie, its perceived chronicity). These 5 measures were scored so that higher values indicated higher levels of stigma, stronger belief in the biomedical underpinnings of depression, stronger endorsement of the psychosocial model, greater feelings of personal control, and a stronger belief that depression is typically chronic.

\section{Statistical Analysis}

Analysis was carried out using Stata 11.0 (StataCorp, College Station, Texas). Scale development was aided by principal components factor analysis. Stata's survey commands were used to yield appropriate standard errors and population parameter estimates. Adults were sampled from 2 strata: those with and those without a self-reported depression history. BRFSS survey weights were used when estimating population parameters, but they were modified to adjust for our oversampling of individuals with a depression history and to reflect the inverse of the probability of selection. Descriptive statistics were used to profile the sample and characterize respondents' reports of barriers to depression disclosure. Associations between categorical variables were assessed with the $\chi^{2}$ test of significance. An index of number of barriers to disclosure was regressed on demographic and health measures to identify significant predictors in a multiple linear regression. In one analysis, respondents were classified as having no/mild depressive symptoms if they had a PHQ-9 score of 0 to 9 . A classification of moderate/severe depressive symptoms was made for respondents with a PHQ-9 score of 10 to 27 . A cutoff score of 10 reflects current practices and research findings. ${ }^{24}$

\section{RESULTS}

\section{Sample Characteristics}

In an unweighted descriptive analysis of the 1,054 respondents, the sample overrepresented women, older individuals, white race, and individuals of higher socioeconomic status relative to the California population as a whole (Table 1). The unweighted sample mean on the PHQ-9 was $4.34(\mathrm{SD}=5.01$, theoretical range $=0-27)$; the estimated population mean was 3.77 (95\% confidence interval $[\mathrm{CI}], 3.34-4.19$ ) (data not shown in tabular form).

\section{Perceived Barriers to Care Seeking}

Approximately $57 \%$ of respondents reported that none of the perceived barriers to talking with their primary care physician about depression applied a lot to them, $17 \%$ reported that 1 reason applied, and $26 \%$ indicated that 2 or more reasons applied. Thus, $43 \%$ reported at least 1 barrier to disclosure. The unweighted sample mean on the Perceived Barriers Index was $1.13(\mathrm{SD}=1.90)_{\text {; }}$ the weighted population estimate was 1.25 (95\% CI, 1.04-1.45). Table 2 reports the unweighted and weighted percentage of respondents indicating that each reason for not seeking help did not apply to them, applied a little, or applied a lot. The most common barriers (based on respondents' reporting that each reason applied a lot) included the possibility of being placed on medication (23\%), the belief that it is not the primary care physician's job to deal with emotional issues (16\%), and concerns about medical record confidentiality $(15 \%)$. Other concerns reported by at least $10 \%$ of respondents included fear of referral to a counselor or psychiatrist, and being labeled a psychiatric patient.

\section{Depression History}

In considering reasons for possible nondisclosure, respondents who reported having a history of depres- 
Table 1. Demographic and Health Characteristics of the Sample $(N=1,054)$

\begin{tabular}{|c|c|c|c|c|c|c|c|}
\hline \multirow[b]{2}{*}{$\begin{array}{l}\text { Respondent } \\
\text { Characteristic }\end{array}$} & \multicolumn{2}{|c|}{ Unweighted } & \multirow{2}{*}{$\begin{array}{c}\text { Weighted } \\
\text { Population } \\
\text { Estimate } \\
(\%)\end{array}$} & \multirow[b]{2}{*}{$\begin{array}{l}\text { Respondent } \\
\text { Characteristic }\end{array}$} & \multicolumn{2}{|c|}{ Unweighted } & \multirow{2}{*}{$\begin{array}{c}\text { Weighted } \\
\text { Population } \\
\text { Estimate } \\
(\%)\end{array}$} \\
\hline & $\%$ & $\mathrm{n}$ & & & $\%$ & n & \\
\hline Demographic & & & & Demographic & & & \\
\hline Female & 67.7 & 714 & 58.5 & Relational status & & & \\
\hline Age, y & & & & Married & 50.0 & 527 & 60.7 \\
\hline $18-29$ & 4.5 & 47 & 15.1 & Not married but partnered & 4.8 & 51 & 6.9 \\
\hline $30-39$ & 9.2 & 97 & 14.3 & Separated or divorced & 21.4 & 226 & 11.8 \\
\hline $40-49$ & 19.6 & 207 & 24.2 & Widow/widower & 11.8 & 124 & 6.4 \\
\hline $50-59$ & 22.9 & 241 & 17.8 & Never married & 12.0 & 126 & 14.2 \\
\hline$>60$ & 43.8 & 461 & 28.6 & Health situation & & & \\
\hline White race & 90.5 & 954 & 85.3 & Ever been treated for & 45.1 & 475 & 29.5 \\
\hline Culturally or ethnically Hispanic & 12.7 & 134 & 24.5 & depression & & & \\
\hline Education & & & & $\begin{array}{l}\text { Currently under treatment } \\
\text { for depression }\end{array}$ & 21.6 & 228 & 16.3 \\
\hline High school or less & 18.1 & 191 & 25.1 & Family history of depression & 52.7 & 555 & 43.0 \\
\hline Some college/technical school & 29.6 & 312 & 27.6 & General health perception & & & \\
\hline College graduate & 52.2 & 550 & 47.3 & Excellent & 17.9 & 189 & 17.9 \\
\hline Household income & & & & Very good & 38.5 & 406 & 37.1 \\
\hline$<\$ 20,000$ & 15.6 & 164 & 12.7 & Good & 27.0 & 285 & 29.5 \\
\hline$\$ 20,000-\$ 34,999$ & 13.9 & 146 & 12.6 & Fair & 12.0 & 126 & 12.2 \\
\hline$\$ 35,000-\$ 49,999$ & 12.3 & 130 & 10.7 & Poor & 4.6 & 48 & 3.4 \\
\hline$\$ 50,000-\$ 74,999$ & 16.2 & 171 & 17.9 & Have regular source of care & 88.0 & 928 & 81.3 \\
\hline$\$ 75,000-\$ 100,000$ & 17.3 & 182 & 18.1 & Have health insurance & 93.7 & 988 & 91.2 \\
\hline$>\$ 100,000$ & 22.1 & 233 & 26.1 & & & & \\
\hline Unsure/declined to answer & 2.7 & 28 & 1.9 & & & & \\
\hline \multicolumn{8}{|l|}{ Employment status } \\
\hline Employed for wages & 35.9 & 378 & 45.6 & & & & \\
\hline Self-employed & 11.6 & 122 & 11.2 & & & & \\
\hline Out of work & 5.8 & 61 & 5.7 & & & & \\
\hline Homemaker & 8.6 & 91 & 9.7 & & & & \\
\hline Student & 2.1 & 22 & 4.8 & & & & \\
\hline Retired & 27.9 & 294 & 18.8 & & & & \\
\hline Unable to work & 8.2 & 86 & 4.3 & & & & \\
\hline
\end{tabular}

sion were more likely than those with no history to be concerned about medical record confidentiality $(P=.041)$ and losing emotional control $(P=.007)$ (Table 3 ). In contrast, respondents with no history of depression were more concerned about being treated with medication $(P=.009)$, more likely to believe that it is not the primary care physician's job to treat depression $(P=.040)$, and more worried about being referred to a psychiatrist if they talked to their doctor about their depression $(P=.036)$. Overall, on the Perceived Barriers Index, respondents with a history of depression did not report more reasons as applying a lot to them $($ mean $=1.09, \mathrm{SD}=1.81)$ than respondents with no such history $($ mean $=1.16, \mathrm{SD}=1.96 ; P=.50)$.

\section{Current Symptoms}

For 10 of 11 barriers, respondents with moderate to severe symptoms $(n=153)$ were significantly more likely than respondents without such symptoms $(n=899)$ to report that the reason applied a lot to them (Table 4).

\section{Predictors of Perceived Barriers to Disclosure of Depression}

Predictors of perceived barriers to disclosure were examined via survey-weighted linear regression analysis in which the Perceived Barriers Index served as the dependent variable (Table 5). Endorsing a larger number of potential barriers to depression disclosure was associated with 4 demographic variables: being female, being Hispanic, having less education, and having less income. Four depression-related variables were predictive of reporting more perceived barriers to disclosure: severity of depression symptoms at the time of the survey, having no family history of depression, believing that depression is a stigmatizing condition, and believing that one should be able to control one's depressive state (adjusted $R^{2}=.31, P<.001$ ). 


\section{DISCUSSION}

Encouraging patients to disclose their symptoms to physicians is among the most direct strategies for increasing the recognition and treatment of depression in primary care. ${ }^{9,10,29}$ More than two-fifths of respondents in this population-based survey subscribed to beliefs that may inhibit such disclosure. Concern that the physician would prescribe antidepressants was the leading reason for nondisclosure of depression, far surpassing concerns about referral for psychotherapy. These findings parallel results from other studies, which have documented a preference for psychotherapy over antidepressants, ${ }^{18}$ but they also suggest that

\section{Table 2. Unweighted and Weighted Distribution of Reasons for Not Seeking Help}

\begin{tabular}{|c|c|c|c|c|c|}
\hline \multirow{2}{*}{$\begin{array}{l}\text { Reason for } \\
\text { Nondisclosure } \\
\text { (Item Label) }\end{array}$} & \multirow[b]{2}{*}{ Response } & \multicolumn{2}{|c|}{$\begin{array}{l}\text { Unweighted } \\
\text { Analysis }\end{array}$} & \multicolumn{2}{|c|}{$\begin{array}{l}\text { Weighted } \\
\text { Estimates }\end{array}$} \\
\hline & & $\%$ & $n$ & $\%$ & $95 \% \mathrm{Cl}$ \\
\hline \multirow{3}{*}{$\begin{array}{l}\text { The doctor might put me on } \\
\text { medicines that I'd rather not } \\
\text { take (medication aversion) }\end{array}$} & Does not apply & 57.3 & 602 & 54.6 & $49.9-59.2$ \\
\hline & Applies a little & 23.4 & 246 & 22.5 & $19.1-26.3$ \\
\hline & Applies a lot & 19.2 & 202 & 22.9 & $18.8-27.5$ \\
\hline \multirow{3}{*}{$\begin{array}{l}\text { I do not feel it is my doctor's } \\
\text { job to deal with emotional } \\
\text { problems (not doctor's job) }\end{array}$} & Does not apply & 73.3 & 773 & 71.0 & $66.4-75.2$ \\
\hline & Applies a little & 14.1 & 149 & 13.4 & $10.9-16.5$ \\
\hline & Applies a lot & 12.5 & 132 & 15.6 & $12.0-20.0$ \\
\hline \multirow{3}{*}{$\begin{array}{l}\text { My medical records might be } \\
\text { seen by others such as an } \\
\text { employer (medical records) }\end{array}$} & Does not apply & 71.5 & 753 & 70.3 & $66.1-74.3$ \\
\hline & Applies a little & 13.2 & 139 & 14.3 & $11.4-17.7$ \\
\hline & Applies a lot & 15.3 & 161 & 15.4 & $12.5-18.9$ \\
\hline \multirow{3}{*}{$\begin{array}{l}\text { The doctor might send me to } \\
\text { a counselor, psychologist or } \\
\text { social worker (counseling) }\end{array}$} & Does not apply & 75.8 & 797 & 74.0 & $69.6-78.0$ \\
\hline & Applies a little & 11.8 & 124 & 12.3 & $9.8-15.4$ \\
\hline & Applies a lot & 12.4 & 130 & 13.7 & $10.4-17.7$ \\
\hline \multirow{3}{*}{$\begin{array}{l}\text { The doctor might send me to } \\
\text { a psychiatrist (psychiatrist) }\end{array}$} & Does not apply & 76.0 & 800 & 73.9 & $69.4-78.0$ \\
\hline & Applies a little & 12.1 & 127 & 12.7 & $10.0-15.9$ \\
\hline & Applies a lot & 11.9 & 125 & 13.4 & 10.1-17.5 \\
\hline \multirow{3}{*}{$\begin{array}{l}\text { I would not want to be consid- } \\
\text { ered a 'psychiatric patient' } \\
\text { (psychiatric patient) }\end{array}$} & Does not apply & 69.8 & 734 & 70.5 & $66.1-74.6$ \\
\hline & Applies a little & 17.4 & 183 & 17.7 & $14.4-21.6$ \\
\hline & Applies a lot & 12.8 & 135 & 11.8 & $9.2-15.0$ \\
\hline \multirow{3}{*}{$\begin{array}{l}\text { I would not want to tell pri- } \\
\text { vate information to my doc- } \\
\text { tor (private information) }\end{array}$} & Does not apply & 84.3 & 888 & 80.2 & $75.7-84.0$ \\
\hline & Applies a little & 9.8 & 103 & 10.7 & $8.0-14.2$ \\
\hline & Applies a lot & 6.0 & 63 & 9.1 & $6.3-12.9$ \\
\hline \multirow{3}{*}{$\begin{array}{l}\text { I might cry or become too } \\
\text { emotional during the visit } \\
\text { (emotional control) }\end{array}$} & Does not apply & 77.3 & 814 & 78.0 & $73.8-81.6$ \\
\hline & Applies a little & 15.5 & 163 & 14.4 & $11.3-18.2$ \\
\hline & Applies a lot & 7.2 & 76 & 7.6 & $5.6-10.4$ \\
\hline \multirow{3}{*}{$\begin{array}{l}\text { I would not know how to } \\
\text { bring up the topic of } \\
\text { depression to my doctor } \\
\text { (topic introduction) }\end{array}$} & Does not apply & 82.7 & 870 & 80.5 & $76.3-84.1$ \\
\hline & Applies a little & 11.5 & 121 & 13.1 & $10.2-16.7$ \\
\hline & Applies a lot & 5.8 & 61 & 6.4 & $4.2-9.6$ \\
\hline \multirow{3}{*}{$\begin{array}{l}\text { I would not want to distract } \\
\text { the doctor from taking care } \\
\text { of my physical health prob- } \\
\text { lems (distraction of doctor) }\end{array}$} & Does not apply & 86.7 & 914 & 86.7 & $83.2-89.7$ \\
\hline & Applies a little & 7.3 & 77 & 8.0 & $5.6-11.3$ \\
\hline & Applies a lot & 6.0 & 63 & 5.3 & $3.8-7.3$ \\
\hline \multirow{3}{*}{$\begin{array}{l}\text { The doctor might think less } \\
\text { of me if I brought up my } \\
\text { depression symptoms (loss } \\
\text { of esteem) }\end{array}$} & Does not apply & 86.7 & 914 & 87.2 & $83.7-90.0$ \\
\hline & Applies a little & 9.3 & 98 & 9.3 & $6.8-12.6$ \\
\hline & Applies a lot & 4.0 & 42 & 3.6 & $2.3-5.4$ \\
\hline \multicolumn{6}{|l|}{$\mathrm{Cl}=$ confidence interval. } \\
\hline \multicolumn{6}{|c|}{$\begin{array}{l}\text { Note: Reasons have been sorted by percentage of the population estimated to believe the reason applies a lo } \\
\text { to them. }\end{array}$} \\
\hline
\end{tabular}

patients lack confidence in their ability to negotiate an acceptable plan of care that reflects their treatment preferences.

Having a history of depression treatment was associated with the type of reasons for nondisclosure but not the number of reasons. Individuals with a history of depression treatment were actually less concerned about treatment issues (eg, the possibility that requests for help would lead to a prescription or mental health referral) but more concerned about privacy and loss of emotional control. Disclosing distress to the physician arouses strong emotions, which persons who have disclosed in the past might better anticipate. Further-

more, persons with a history of depression treatment may think of themselves as more emotionally labile than those without such a history. It is also possible that a prior attempt at disclosure resulted in some of the barriers respondents endorsed. Future research should clarify the mechanisms in the formation of barrier perceptions and persons' reactions to these perceptions.

Ironically, those who most subscribed to potential reasons for not talking to a primary care physician about their depression tended to be those who had the greatest potential to benefit from such conversations - individuals with moderate to severe depressive symptoms. A despondent mood state can diminish self-efficacy ${ }^{20}$ and may make individuals question their ability to accomplish even simple tasks, such as making arrangements to see a doctor. It is also possible that depression leads individuals to perceive their circumstances and competencies more negatively. Longitudinal research is needed to clarify the causal relationship between symptom severity and perceived barriers to disclosure.

The significant predictors of perceived barriers to care seeking identified in this study are generally consistent with prior research. Hispanics, for example, endorsed more reasons for not talking with their doctor. Hispanics make 
less-frequent use of mental health services compared with non-Hispanic whites ${ }^{30,31}$ and may prefer informal sources of care and support. ${ }^{32,33}$ Not surprisingly, holding self-blaming attributions about depression and

Table 3. Unweighted Percentage of Respondents With vs Without a History of Depression Treatment Who Reported That a Reason for Not Seeking Depression Care Applies a Lot

\begin{tabular}{|c|c|c|c|c|c|}
\hline \multirow{2}{*}{$\begin{array}{l}\text { Reason for } \\
\text { Nondisclosure }^{a}\end{array}$} & \multicolumn{2}{|c|}{$\begin{array}{l}\text { History of } \\
\text { Treatment }^{\mathrm{b}} \\
(\mathrm{n}=475)\end{array}$} & \multicolumn{2}{|c|}{$\begin{array}{l}\text { No History } \\
\text { of Treatment } \\
(n=579)\end{array}$} & \multirow[b]{2}{*}{$P$ Value ${ }^{c}$} \\
\hline & $\%$ & $\mathrm{n}$ & $\%$ & $\mathrm{n}$ & \\
\hline Medication aversion & 15.6 & 74 & 22.2 & 128 & .009 \\
\hline Not doctor's job & 10.1 & 48 & 14.5 & 84 & .040 \\
\hline Medical records & 17.9 & 85 & 13.1 & 76 & .041 \\
\hline Counseling referral & 11.4 & 54 & 13.1 & 76 & .423 \\
\hline Psychiatrist referral & 9.5 & 45 & 13.9 & 80 & .036 \\
\hline Psychiatric patient & 13.7 & 65 & 12.1 & 70 & .511 \\
\hline Private information & 4.4 & 21 & 7.3 & 42 & .072 \\
\hline Emotional control & 9.7 & 46 & 5.2 & 30 & .007 \\
\hline Topic introduction & 5.7 & 27 & 5.9 & 34 & 1.00 \\
\hline Distract of doctor & 5.9 & 28 & 6.0 & 35 & 1.00 \\
\hline Loss of esteem & 4.8 & 23 & 3.3 & 19 & .258 \\
\hline \multicolumn{6}{|c|}{$\begin{array}{l}\text { b Respondents were classified into the history }(n=475) \text { or no history }(n=579) \text { groups based on } \\
\text { their answer to the question, "Have you, personally, ever been treated for depression by a health } \\
\text { care provider? A health care provider could be a medical doctor or a mental health professional, } \\
\text { such as a psychiatrist, psychologist, social worker, or counselor." } \\
\text { " Probability values are based on the } \chi^{2} \text { test with continuity correction. }\end{array}$} \\
\hline
\end{tabular}

Table 4. Unweighted Percentage of Respondents Without vs With Moderate or Severe Depressive Symptoms Who Reported That a Reason for Not Seeking Depression Care Applies a Lot

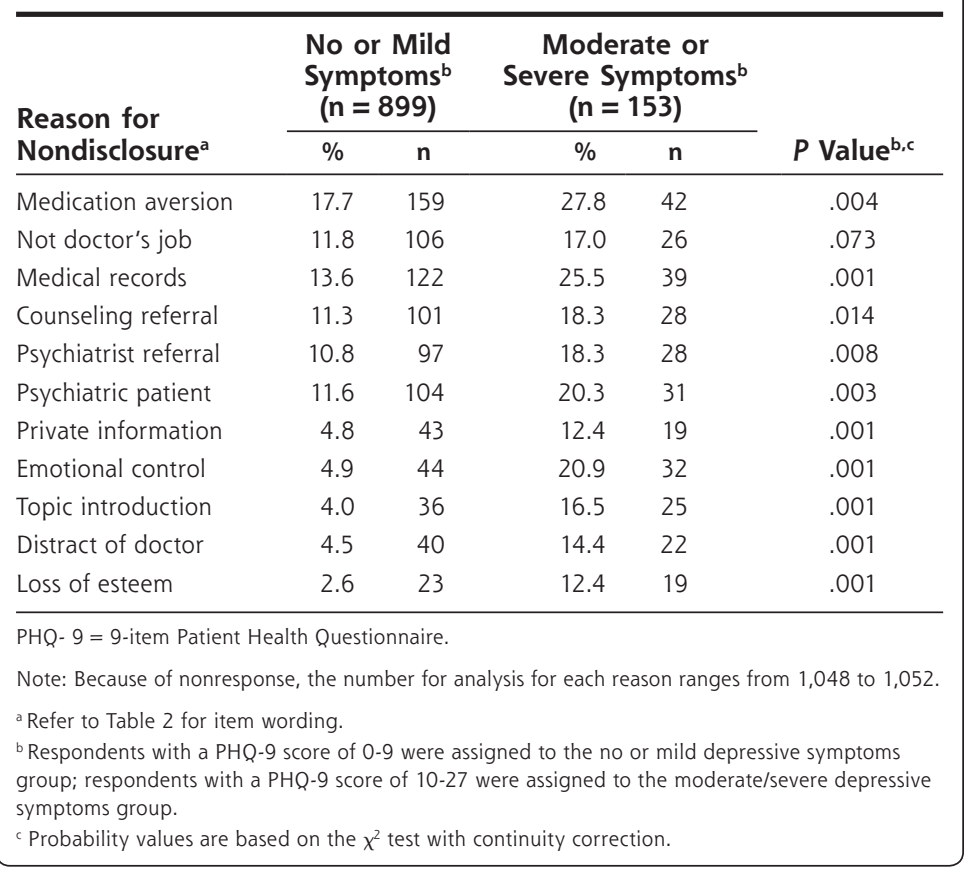

believing that one should be able to control one's own symptoms of depression are associated with unwillingness to discuss depressive symptoms with physicians. ${ }^{13}$ Interestingly, having a family member or friend who had gone through depression was associated with fewer perceived obstacles to care, but having a personal history of depression was not. ${ }^{34}$ Future studies should consider how vicarious and personal experiences foster different expectations about the process and outcomes of depression care. The paradoxical finding that women identify with more barriers to care seeking while simultaneously being more likely to seek treatment deserves future research attention. ${ }^{35}$ This effect should be interpreted with caution, because it emerges only in the adjusted analysis. It may be that this ambivalence and doubt are motivating some women to seek and accept treatment. Alternatively, the finding may reflect women's greater willingness to communicate honestly about depression.

There is good news in these findings -7 of 8 respondents believed that the primary care physician is an appropriate source of depression care. Furthermore, few respondents reported that they would decline to talk with their doctor about depression because of embarrassment, privacy concerns, or loss of face. Surprisingly, only about $6 \%$ of respondents doubted their ability to initiate a conversation about depression with their doctor. Future research should assess whether such reticence is truly this low or whether this finding reflects an externalization of depression stigma.

This study has limitations. First, the survey response rate is lower than what one might hope for, albeit similar to the responses rates reported in other BRFSS surveys. ${ }^{36}$ This response rate, when weighted, may introduce unknown bias to the results. Second, the sample was limited to California adults. Third, our reliance on data collection via a telephone survey necessitated use of brief measures, which lowers reliability and precision of measurement. Fourth, we examined only those patient barriers to care seeking that have the potential to be addressed in an office-based educational interven- 


\begin{tabular}{|c|c|c|}
\hline Predictors & Coefficient & $95 \% \mathrm{Cl}$ \\
\hline \multicolumn{3}{|l|}{ Demographic variables } \\
\hline Age (in years) & .001 & -.001 to .003 \\
\hline Female & $.080^{\mathrm{a}}$ & .014 to .146 \\
\hline Married or partnered & -.003 & -.072 to .065 \\
\hline Nonwhite race & .025 & -.081 to .130 \\
\hline Hispanic & $.129^{b}$ & .033 to .244 \\
\hline \multicolumn{3}{|l|}{ Education } \\
\hline High school or less & - & - \\
\hline Some college/technical & $-.120^{a}$ & -.223 to -.016 \\
\hline College graduate & -.058 & -.163 to .047 \\
\hline \multicolumn{3}{|l|}{ Income } \\
\hline$\$ 0-\$ 34,999$ & - & - \\
\hline$\$ 35,000-\$ 75,000$ & $-.173^{c}$ & -.276 to -.069 \\
\hline$>\$ 75,000$ & $-.120^{a}$ & -.230 to -.010 \\
\hline \multicolumn{3}{|l|}{ Health/depression variables } \\
\hline General health perception & .017 & -.021 to .055 \\
\hline Depression symptoms (PHQ-9) & $.019^{c}$ & .009 to .029 \\
\hline Past diagnosis & .035 & -.035 to 1.05 \\
\hline Family history & $-.078^{a}$ & -.140 to -.015 \\
\hline Stigma & $.136^{c}$ & .092 to .181 \\
\hline Biomedical causes & -.005 & -.071 to .061 \\
\hline Psychosocial causes & -.011 & -.057 to .035 \\
\hline Controllable & $.074^{b}$ & .024 to .123 \\
\hline Timeline (usually $>1$ y) & .040 & -.026 to .105 \\
\hline Health insurance & -.093 & -.266 to .079 \\
\hline Regular source of care & -.024 & -.134 to .086 \\
\hline \multicolumn{3}{|c|}{ PHQ-9 = 9-item Patient Health Questionnaire. } \\
\hline \multicolumn{3}{|c|}{ Note: Because of nonresponse, $n=982$ for this analysis. } \\
\hline $\begin{array}{l}\text { a } P<.05 . \\
\text { b } P<.01 . \\
\text { c } P<.001\end{array}$ & & \\
\hline
\end{tabular}

tion. Fifth, we did not address the needs of those who may have been willing to request help but failed to recognize that their symptoms could be indicative of depression. ${ }^{13}$

In this survey from California, $43 \%$ of patients strongly endorsed one or more reasons for not disclosing depression to their primary care physician. This finding underscores the need to develop and test office-based interventions that address these patient concerns and motivate disclosure of depression. Toward this end we are currently evaluating 2 officebased approaches encouraging patients with depression symptoms to begin a conversation with their doctors. The effectiveness of multimedia approaches, standardized questionnaires, and explicit inquiry by the physician about depressive symptoms in facilitating disclosure of depression may vary by patient. Even so, it is clear that left to their own devices, many patients will not report important symptoms spontaneously.
To read or post commentaries in response to this article, see it online at http://www.annfammed.org/cgi/content/full/9/5/439.

Key words: Depression; primary health care; disclosure; treatment; communication barriers; social stigma

Submitted July 26, 2010; submitted, revised, April 1, 2011; accepted April 19, 2011.

Author affiliations: Departments of Communication and Public Health Sciences, University of California, Davis, Davis, California (Bell); Center for Healthcare Policy and Research, University of California, Davis, Sac ramento, California (Bell, Franks, Fernandez y Garcia, Kravitz); Department of Family and Community Medicine, University of California, Davis, School of Medicine, Sacramento, California (Franks); Department of Psychiatry, University of Rochester Medical Center, Rochester, New York (Duberstein); Rochester Center for the Improvement of Communication in Health Care, Departments of Family Medicine and Psychiatry, Division of Oncology and School of Nursing, University of Rochester Medical Center, Rochester, New York (Epstein); Division of General Internal Medicine, Department of Medicine, University of California, San Francisco, San Francisco, California (Feldman); Department of Pediatrics, University of California, Davis, Sacramento, California (Fernandez y Garcia); Division of General Medicine, Department of Internal Medicine, University of California, Davis, Sacramento, California (Kravitz).

Funding support: This project was supported by a grant from the National Institute of Mental Health (1R01MH079387-01 and 1R01MH079387-01-DS).

Disclaimer: The sponsor was not involved in data collection, analysis, interpretation, writing of the report, or decision to submit the paper for publication.

Acknowledgements: The authors gratefully acknowledge the assistance of Christina Slee.

\section{References}

1. Barbui C, Tansella M. Identification and management of depression in primary care settings. A meta-review of evidence. Epidemiol Psychiatr Soc. 2006;15(4):276-283.

2. Young AS, Klap R, Sherbourne CD, Wells KB. The quality of care for depressive and anxiety disorders in the United States. Arch Gen Psychiatry. 2001;58(1):55-61.

3. Kessler RC, Demler O, Frank RG, et al. Prevalence and treatment of mental disorders, 1990 to 2003. N Engl J Med. 2005;352(24): 2515-2523.

4. Cepoiu M, McCusker J, Cole MG, Sewitch M, Belzile E, Ciampi A. Recognition of depression by non-psychiatric physicians-a systematic literature review and meta-analysis. J Gen Intern Med. 2008;23(1):25-36.

5. Baik SY, Bowers BJ, Oakley LD, Susman JL. The recognition of depression: the primary care clinician's perspective. Ann Fam Med. 2005;3(1):31-37.

6. Collins KA, Westra HA, Dozois DJ, Burns DD. Gaps in accessing treatment for anxiety and depression: challenges for the delivery of care. Clin Psychol Rev. 2004;24(5):583-616.

7. Saver BG, Van-Nguyen V, Keppel G, Doescher MP. A qualitative study of depression in primary care: missed opportunities for diagnosis and education. J Am Board Fam Med. 2007;20(1):28-35.

8. Levinson W, Gorawara-Bhat R, Lamb J. A study of patient clues and physician responses in primary care and surgical settings. JAMA. 2000;284(8):1021-1027. 
9. Kravitz RL, Epstein RM, Feldman MD, et al. Influence of patients' requests for direct-to-consumer advertised antidepressants: a randomized controlled trial. JAMA. 2005;293(16):1995-2002.

10. Tylee A, Freeling P, Kerry S, Burns T. How does the content of consultations affect the recognition by general practitioners of major depression in women? Br J Gen Pract. 1995;45(400):575-578.

11. Rochlen AB, Paterniti DA, Epstein RM, Duberstein P, Willeford L, Kravitz RL. Barriers in diagnosing and treating men with depression: a focus group report. Am J Mens Health. 2010;4(2):167-175.

12. Bell RA, Paterniti DA, Azari R, et al. Encouraging patients with depressive symptoms to seek care: a mixed methods approach to message development. Patient Educ Couns. 2010;78(2):198-205.

13. Epstein RM, Duberstein PR, Feldman MD, et al. "I didn't know what was wrong:" how people with undiagnosed depression recognize, name and explain their distress. J Gen Intern Med. 2010;25 (9):954-961.

14. Kravitz RL, Paterniti DA, Epstein RM, et al. Relational barriers to depression help-seeking in primary care. Patient Educ Couns. 2011; 82(2):207-213.

15. Cape J, McCulloch Y. Patients' reasons for not presenting emotional problems in general practice consultations. Br J Gen Pract. 1999;49(448):875-879.

16. Kadam UT, Croft P, McLeod J, Hutchinson M. A qualitative study of patients' views on anxiety and depression. Br J Gen Pract. 2001; 51(466):375-380.

17. Dwight-Johnson M, Sherbourne CD, Liao D, Wells KB. Treatment preferences among depressed primary care patients. J Gen Intern Med. 2000;15(8):527-534.

18. Backenstrass M, Joest K, Frank A, Hingmann S, Mundt C, Kronmüller KT. Preferences for treatment in primary care: a comparison of nondepressive, subsyndromal and major depressive patients. Gen Hosp Psychiatry. 2006;28(2):178-180.

19. Mohr DC, Hart SL, Howard I, et al. Barriers to psychotherapy among depressed and nondepressed primary care patients. Ann Behav Med. 2006;32(3):254-258.

20. Bandura A. Self efficacy. In: Friedman H, ed. Encyclopedia of Mental Health. San Diego, CA: Academic Press; 1998.

21. Giel R, Koeter MW, Ormel J. Detection and referral of primary-care patients with mental health problems: the second and third filter. In: Goldberg D, Tantum D, eds. The Public Health Impact of Mental Disorder. Toronto: Hogrefe and Huber; 1990:25-34.

22. Karasz A, Sacajiu G, Garcia N. Conceptual models of psychological distress among low-income patients in an inner-city primary care clinic. J Gen Intern Med. 2003;18(6):475-477.
23. Bergner M, Rothman ML. Health status measures: an overview and guide for selection. Annu Rev Public Health. 1987;8:191-210.

24. Kroenke K, Spitzer RL, Williams JB, Löwe B. The Patient Health Questionnaire Somatic, Anxiety, and Depressive Symptom Scales: a systematic review. Gen Hosp Psychiatry. 2010;32(4):345-359.

25. Spitzer RL, Kroenke K, Williams JB. Validation and utility of a selfreport version of PRIME-MD: the PHQ primary care study. Primary Care Evaluation of Mental Disorders. Patient Health Questionnaire. JAMA. 1999;282(18):1737-1744

26. Fogel J, Ford DE. Stigma beliefs of Asian Americans with depression in an internet sample. Can J Psychiatry. 2005;50(8):470-478.

27. Fortune G, Barrowclough C, Lobban F. Illness representations in depression. Br J Clin Psychol. 2004;43(Pt 4):347-364.

28. Brown C, Battista DR, Sereika SM, Bruehlman RD, Dunbar-Jacob J, Thase ME. Primary care patients' personal illness models for depression: relationship to coping behavior and functional disability. Gen Hosp Psychiatry. 2007;29(6):492-500.

29. Carney PA, Eliassen MS, Wolford GL, Owen M, Badger LW, Dietrich AJ. How physician communication influences recognition of depression in primary care. J Fam Pract. 1999;48(12):958-964.

30. Peifer KL, Hu T, Vega W. Help seeking by persons of Mexican origin with functional impairments. Psychiatr Serv. 2000;51(10): 1293-1298.

31. Wang PS, Lane M, Olfson M, Pincus HA, Wells KB, Kessler RC. Twelve-month use of mental health services in the United States: results from the National Comorbidity Survey Replication. Arch Gen Psychiatry. 2005;62(6):629-640.

32. Cooper LA, Gonzales JJ, Gallo JJ, et al. The acceptability of treatment for depression among African-American, Hispanic, and white primary care patients. Med Care. 2003;41(4):479-489.

33. Cabassa LJ, Zayas LH. Latino immigrants' intentions to seek depression care. Am J Orthopsychiatry. 2007;77(2):231-242.

34. Schomerus G, Matschinger $H$, Angermeyer MC. The stigma of psychiatric treatment and help-seeking intentions for depression. Eur Arch Psychiatry Clin Neurosci. 2009;259(5):298-306.

35. Carragher N, Adamson G, Bunting B, McCann S. Treatment-seeking behaviours for depression in the general population: results from the National Epidemiologic Survey on Alcohol and Related Conditions. J Affect Disord. 2010;121(1-2):59-67.

36. Groves RM, Fowler FJ, Couper MP, Lepkowski JM, Singer E, Tourangeau R. Survey Methodology. 2nd ed. Hoboken, NJ: Wiley; 2009. 